\title{
Morphological and genetic polymorphism of new Diacyclops taxonomic group from Lake Baikal (Copepoda: Cyclopoida)
}

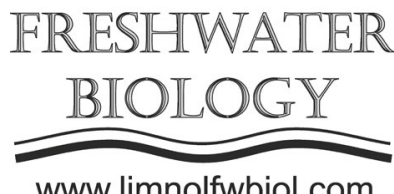

\author{
Mayor T.Yu., Zaidykov I.Yu.*, Kirilchik S.V. \\ Limnological Institute, Siberian Branch of the Russian Academy of Sciences, Ulan-Batorskaya Str., 3, Irkutsk, 664033, Russia
}

\begin{abstract}
In this study, we have performed morphological and molecular analyses of a phylogenetic group (VIG2) in the complex of Baikal cyclopoids that are morphologically similar to Diacyclops versutus, D. improcerus and D. galbinus. The first internal transcribed spacer (ITS1) and the mitochondrial cytochrome c oxidase subunit I (COI) were chosen as molecular markers. We have measured 27 morphological features and obtained values of 18 morphometric characteristics. We present an illustrated description of the females VIG2. We show that representatives of VIG2 belong to the new taxonomic group Diacyclops in Lake Baikal. Genetic and morphometric differences in the representatives of VIG2 from four locations are comparable to the intraspecific level of differences.
\end{abstract}

Keywords: Copepoda, Diacyclops, morphometry, Lake Baikal, COI, ITS

\section{Introduction}

The Cyclopoida in Baikal represent one of the numerous and highly endemic groups of arthropods in the number of species yielding to amphipods, ostracods, and harpacticoids (Timoshkin, 2001). In the number of species, two taxonomically complex genera Acanthocyclops Kiefer, 1927 and Diacyclops Kiefer, 1927 (Mazepova, 1978; Sheveleva et al., 2012) dominate among the Baikal cyclopoids. Three endemic species from this group, D. versutus (Mazepova, 1962), D. improcerus (Mazepova, 1950), and D. galbinus (Mazepova, 1962), are widespread in the Baikal littoral zone, occur together during sampling and have a similar morphology, which previously suggested their close relationship (Mazepova, 1978).

The first results of the molecular phylogenetic study of Baikal cyclopoids identified a discordance between molecular and morphological data (Mayor et al., 2017; 2018). Among the analyzed specimens similar in morphology to $D$. versutus, $D$. improcerus, and D. galbinus, there were three phylogenetic groups with an unclear taxonomic status (VIG1-3). The acronym VIG stands for the first letters of the species name of the three species studied (V - versutus, I - improcerus, G - galbinus). The VIG1 and VIG2 phylogenetic groups included 5 and 6 nucleotide sequences of individuals morphologically determined as $D$. versutus ( 3 and 1 nucleotide sequences), D. improcerus (1 and 4), and $D$. galbinus (1 and 1), respectively. The VIG3 included 2 nucleotide sequences: 1 for $D$. galbinus and 1 for $D$. improcerus. The appearance of phylogenetic groups can be due to an insufficient description of the Baikal cyclopoids. The identified case can also be due to the presence of cryptic speciation among endemic Baikal cyclopoids or mitochondrial introgression in the group of D. versutus / D. improcerus / D. galbinus. A series of studies show the presence of cryptic species for Cyclopoida (Monchenko, 2000; Blaha et al., 2010; Ueda et al., 2011; Karanovic and Krajicek, 2012; Sukhikh and Alekseev, 2015). As a rule, sibling species are identified accidentally during molecular studies, and, in order to obtain their taxonomic description, it is advisable to carry out additional analysis of morphology in combination with the use of molecular methods.

The aim of this work is to assess the morphological and genetic polymorphism of cyclopoids that are similar in morphology to $D$. versutus / D. improcerus / D. galbinus constituting one phylogroup (VIG2) and inhabiting the Southern Baikal.

\section{Material and methods}

Samples were collected in Lake Baikal from depths of up to $15 \mathrm{~m}$ in April - June 2018 using a net and dredge. Collecting sites were chosen in the vicinity of the Bolshoye Goloustnoe $\left(52^{\circ} 02^{\prime} \mathrm{N} 105^{\circ} 24^{\prime} \mathrm{E}\right)$, Bolshiye Koty $\left(51^{\circ} 54^{\prime} \mathrm{N} 105^{\circ} 04^{\prime} \mathrm{E}\right)$, and Listvyanka $\left(51^{\circ} 51^{\prime} \mathrm{N}\right.$ $104^{\circ} 52^{\prime} \mathrm{E}$ ) settlements as well as the town of Slyudyanka $\left(51^{\circ} 40^{\prime} \mathrm{N} 103^{\circ} 42^{\prime} \mathrm{E}\right)$. Samples with live crustaceans were handled in the laboratory, adult females with egg sacs were fixed in $96 \%$ ethanol and stored at $-20{ }^{\circ} \mathrm{C}$. The taxonomic identification of cyclopoids was performed using the identification table by G.F. Mazepova (1978).

*Corresponding author.

E-mail address: igorrock11@mail.ru (I. Yu. Zaidykov)

(C) Author(s) 2019. This work is distributed under the Creative Commons Attribution 4.0 License. 


\section{Morphological analysis}

Morphological features were measured according to the Kozminski scheme (Kozminski, 1936) using a MSP-1 stereomicroscope (LOMO, Russia), an Olympus CX 41 microscope (Olympus, Japan), a Levenhuk M 800 Plus digital camera and a LevenhukLite software (Levenhuk, Inc., USA). The length of the body was obtained by summing the lengths of cephalothorax, thorax, and abdomen. For the fourth pair of swimming legs, the length (Lenp3P4) and width (Wenp3P4) of the distal endopodite segment, the length of the same segment from the beginning to the point of attachment of the outer seta (Lo), the length of the internal apical spine(IAS), and the length of the external apical spine (EAS) on the distal segment were measured. For the fifth pair of swimming legs, the length (LP5) and width (WP5) of the distal segment, the length of the spine (LSpP5), and seta on the distal segment (LSeP5) were measured. The setae on the caudal branches were designated according to Dussart and Defaye (2006).

Statistical analyses were performed using the $\mathrm{R}$ v. 3.4.2 software (R Core Team, 2017). The mean error (m) was determined according to the formula (1).

$$
m=S D / \sqrt{N-1}
$$

where SD is the standard deviation and $\mathrm{N}$ is the number of observations. Normality of the distribution of the parameter values was assessed using the ShapiroWilk test. For normally distributed parameter values, the comparison of sampling sets was performed using one-way analysis of variance (one-way ANOVA). Otherwise, a permutation test was used.

For confocal laser scanning microscopy (CLSM), a female was stained with Congo Red overnight and mounted on slide following the procedure described by Michels and Büntzow (2010). The material was scanned using a Carl Zeiss LSM 710 laser confocal microscope (Zeiss, Germany); lens: Plan-Apochromat $20 \times / 0.8$ and $63 \times / 1.40$ Oil DIC M27; filters: 570 - $670 \mathrm{~nm}$; lasers: $561 \mathrm{~nm}: 3.0 \%$. For scanning electron microscopy (SEM), specimens fixed in 96\% ethanol were dehydrated in 99\% ethanol, transferred into $100 \%$ hexamethyldisiloxan, dried overnight in a fume hood, mounted on stubs, coated with gold, and observed under a Quanta 200 microscope (FEI Company, USA) with accelerating voltage of $15 \mathrm{kV}$ (Laforsch and Tollrian, 2000; Zaidykov and Naumova, 2011).

\section{Molecular genetic analysis}

Total DNA for molecular genetic analysis was isolated from egg sacs or somatic tissue using proteinase $\mathrm{K}$ according to the previously described protocol (Mayor et al., 2010). For PCR, we used universal primers LCO-1490 and HCO-2198 to amplify the COI fragment, and KP2 (5'-AAAAAGCTTCCGTAGGTGAACCTGCG-3') and $5.8 \mathrm{~S}$ (5'-AGCTTGGTGCGTTCTTCATCGA-3') to amplify ITS1 (Folmer et al., 1994; Phillips et al., 2000). Amplification was carried out in a $\mathrm{T} 100^{\mathrm{TM}}$ thermal cycler (BioRad, USA) using PCR reagents from Evrogen (Russia). The reaction occurred in a $1 \mathrm{X}$ Encyclo buffer for PCR in the presence of $3.5 \mathrm{mM}$ magnesium, $5 \mu \mathrm{M}$ of each primer, $0.2 \mathrm{mM}$ of each dNTP and 0.5 units of Encyclo DNA polymerase, and $1 \mu \mathrm{l}$ of DNA-containing mixture. The amplification program included the stage of heating the mixture to $94{ }^{\circ} \mathrm{C}$ for $4 \mathrm{~min}, 35-40$ cycles consisting of the following steps: $94{ }^{\circ} \mathrm{C}$ for $15 \mathrm{~s}, 48{ }^{\circ} \mathrm{C}$ or $55{ }^{\circ} \mathrm{C}$ (for COI and ITS 1 fragments, respectively) for 20 $\mathrm{s}, 72{ }^{\circ} \mathrm{C}$ for $1 \mathrm{~min}$, and the final elongation stage at 72 ${ }^{\circ} \mathrm{C}$ for $4 \mathrm{~min}$. The separation and isolation of amplicons for sequencing from the agarose gel was performed according to the protocol described previously (Mayor et al., 2010). The nucleotide sequences of the target fragments were determined in an ABI 3500 8-capillary genetic analyzer (Thermo Fisher Scientific, USA) using the ABI PRISM BigDye Terminator v. 3.1 sequencing kit.

Alignment of nucleotide sequences, selection of a nucleotide substitution model, calculation of genetic distances and construction of phylogenetic schemes by the maximum likelihood (ML) method were performed with the Mega version 7.0.21 program (Kumar et al., 2017). During alignment of the rDNA nucleotide sequences, the Gblock version 0.91b program was additionally used to remove regions with high divergence (Castresana, 2000). The genetic distances for the COI gene fragment were calculated, taking into account all the positions of the codon. To analyze the COI and ITS1 data sets, respectively, a threeparameter Tamura model supplemented by the share of stable sites (T92 + I) and a two-parameter Kimura model with the gamma distribution (K2P $+\mathrm{G})$ were chosen, taking into account the Akaike information criterion (AIC) and the Bayesian information criterion (BIC). Nodal support for the resulting branches was estimated with 1000 bootstrap replications. DNA polymorphism was evaluated using the DnaSP 5.10.01 program (Rozas et al., 2003). Our previously published nucleotide sequences of Baikal cyclopoids (KT07506365, KT075067-68, and KT075070) and two nucleotide sequences (MK217350-51) kindly provided by Yu. A. Galimova were also included in the set of the analyzed data. One nucleotide sequence (EU877959) was borrowed from the GenBank database as an outgroup.

\section{Results and discussion}

\section{Morphological analysis}

We collected 66 adult females of $D$. sp. in the Southern Baikal. Due to the morphometric analysis, 27 morphological features were measured and values of 18 the morphometric parameters used in Cyclopoida studies were obtained (Monchenko, 1974; Lajus and Alekseev, 2000; Blaha et al., 2010) for statistical analysis (Table 1). Some of these parameters represent the description of $D$. galbinus, $D$. versutus, and $D$. improcerus: LA1/Lcphth, Lf/Wf, Tl position, Lenp3P4/ Wenp3P4, IAS/EAS, Tmi/Tme. Three more parameters: $\mathrm{Te} / \mathrm{Ti}, \mathrm{Td} / \mathrm{Te}, \mathrm{Tl} / \mathrm{Wf}$, which G.F. Mazepova (1950; 1962) gave for D. galbinus, D. versutus, and D. improcerus, are additionally defined (Table 2). Parameter values Te/Ti, Lf/Wf, IAS/EAS of D. galbinus, D. versutus, and $D$. improcerus according to the description of these 
Table 1. Morphometric and quantitative morphological parameters of VIG2 from different sampling sets, the results of a single-factor ANOVA (F-criterion) and permutational test of their variability

\begin{tabular}{|c|c|c|c|c|c|c|}
\hline \multirow{2}{*}{ Characteristics } & \multicolumn{4}{|c|}{ Mean $\pm \mathrm{m}$} & \multirow[b]{2}{*}{$\mathbf{F}$} & \multirow[b]{2}{*}{ Pr } \\
\hline & Listvyanka & Slyudyanka & $\begin{array}{c}\text { Bolshoye } \\
\text { Goloustnoe }\end{array}$ & Bolshie Koty & & \\
\hline Body length, $\mu \mathrm{m}$ & $830 \pm 11.0(14)$ & $807 \pm 11.82(16)$ & $817 \pm 9.85(11)$ & $794 \pm 9.44(17)$ & 1.60 & 0.20 \\
\hline LA1/Lcphth, & $1.02 \pm 0.01$ & $1.00 \pm 0.02(18)$ & $0.98 \pm 0.01(11)$ & $1.00 \pm 0.01(19)$ & 0.83 & 0.48 \\
\hline Lf/Wf & $3.17 \pm 0.08$ & $3.19 \pm 0.06(20)$ & $3.06 \pm 0.06(11)$ & $3.06 \pm 0.04$ (19) & 1.73 & 0.17 \\
\hline Tl position & $0.79 \pm 0.01$ & $0.79 \pm 0.01$ & $0.80 \pm 0.01(11)$ & $0.77 \pm 0.01$ & 0.65 & 0.59 \\
\hline $\mathrm{Tl} / \mathrm{Te}$ & $0.60 \pm 0.02$ & $0.63 \pm 0.02(19)$ & $0.64 \pm 0.02(11)$ & $0.64 \pm 0.02(19)$ & 0.86 & 0.47 \\
\hline Tmi/Tme & $1.64 \pm 0.02$ & $1.63 \pm 0.02(18)$ & $1.65 \pm 0.02(11)$ & $1.63 \pm 0.02(18)$ & 0.18 & 0.91 \\
\hline Ti/Lf & $0.47 \pm 0.02$ & $0.47 \pm 0.01(20)$ & $0.47 \pm 0.01$ & $0.49 \pm 0.01$ (19) & 0.51 & 0.67 \\
\hline $\mathrm{Ti} / \mathrm{Tmi}$ & $0.11 \pm 0.004(12)$ & $0.11 \pm 0.003(18)$ & $0.11 \pm 0.003(11)$ & $0.11 \pm 0.003(18)$ & 0.17 & $0.69 *$ \\
\hline $\mathrm{Ti} / \mathrm{Tme}$ & $0.19 \pm 0.005(15)$ & $0.19 \pm 0.004(20)$ & $0.18 \pm 0.004(11)$ & $0.19 \pm 0.005$ & 0.24 & $0.67 *$ \\
\hline Ti/Td & $0.66 \pm 0.04$ & $0.61 \pm 0.02(19)$ & $0.59 \pm 0.01$ & $0.58 \pm 0.01(19)$ & 0.76 & $0.52 *$ \\
\hline $\mathrm{Ti} / \mathrm{Te}$ & $0.61 \pm 0.02$ & $0.64 \pm 0.02(20)$ & $0.61 \pm 0.01$ & $0.64 \pm 0.01$ (19) & 0.81 & 0.49 \\
\hline Lenp3P4/Wenp3P4 & $1.44 \pm 0.03(13)$ & $1.40 \pm 0.02(19)$ & $1.40 \pm 0.02(10)$ & $1.45 \pm 0.03(17)$ & 1.05 & 0.38 \\
\hline Lo/Lenp3P4 & $0.62 \pm 0.01$ & $0.63 \pm 0.01(19)$ & $0.65 \pm 0.01(10)$ & $0.64 \pm 0.01(17)$ & 1.95 & $0.11 *$ \\
\hline IAS/EAS & $1.60 \pm 0.03(13)$ & $1.59 \pm 0.04(18)$ & $1.65 \pm 0.05(10)$ & $1.58 \pm 0.02(17)$ & 0.06 & $0.63 *$ \\
\hline IAS/Wenp3P4 & $1.77 \pm 0.07(13)$ & $1.71 \pm 0.04(18)$ & $1.78 \pm 0.03(10)$ & $1.74 \pm 0.03(17)$ & 0.52 & 0.67 \\
\hline IAS/Lenp3P4 & $1.23 \pm 0.05$ & $1.22 \pm 0.02(18)$ & $1.27 \pm 0.02(10)$ & $1.21 \pm 0.02(17)$ & 0.7 & 0.56 \\
\hline LSpP5/LP5 & $1.26 \pm 0.04(12)$ & $1.10 \pm 0.03(18)$ & $1.24 \pm 0.13(9)$ & $1.24 \pm 0.06(18)$ & 2.01 & $0.11 *$ \\
\hline WP5/LSpP5 & $0.35 \pm 0.02(12)$ & - & $0.32 \pm 0.02(9)$ & $0.33 \pm 0.01(18)$ & 0.67 & 0.52 \\
\hline LSeP5/LSpP5 & $1.64 \pm 0.05(10)$ & $1.85 \pm 0.07(16)$ & $1.62 \pm 0.11(9)$ & $1.63 \pm 0.10(18)$ & 0.98 & $0.38 *$ \\
\hline
\end{tabular}

LA1/Lcphth is the ratio of an antennule length to a cephalothorax length. Lf/Wf is the ratio of the length to the width of caudal rami. Tl location is the ratio of a caudal rami length from the beginning to the point of attachment of a lateral seta to the caudal rami length. The brackets indicate the number of specimens for which measurements made and the parameter defined; * - permutation test results.

Table 2. Morphometric and morphological parameters of VIG2, D. versutus, D. galbinus, and D. improcerus

\begin{tabular}{|c|c|c|c|c|}
\hline Parameter & VIG2* & D. versutus $* *$ & D. galbinus $* *$ & D. improcerus ${ }^{* *}$ \\
\hline Body length, $\mu \mathrm{m}$ & $747-902(803)$ & $620-920(770)$ & $730-1000(860)$ & $480-750(610)$ \\
\hline Lf/Wf & $2.80-3.61(3.08)$ & $1.8-3.4(2.5)$ & $2.9-5.4(3.7)$ & $1.8-4.1(3.0)$ \\
\hline $\mathrm{Te} / \mathrm{Ti}$ & $1.36-1.96(1.63)$ & $0.5-1.8(1.2)$ & $0.6-1.8(1.2)$ & $1.0-2.1 \quad(1.6)$ \\
\hline Tmi/Tme & $1.58-1.72(1.64)$ & $1.7-2.2(1.8)$ & $1.3-1.9(1.6)$ & \\
\hline $\mathrm{Td} / \mathrm{Te}$ & $0.97-1.13(1.04)$ & $0.9-1.5(1.2)$ & $0.8-1.2(1.00)$ & - \\
\hline Tl/Wf & $1.02-1.61(1.39)$ & $0.3-0.6(0.5)$ & $1.4-2.0(1,6)$ & \\
\hline Lenp3P4/Wenp3P4 & $1.25-1.56(1.39)$ & $1.0-1.8(1.4)$ & $1.6-3.0(2.0)$ & $1.0-1.4(1.2)$ \\
\hline IAS/EAS & $1.46-2.02(1.63)$ & $0.6-1.2(1.0)$ & $1.1-1.8(1.3)$ & $1.0-1.9(1.35)$ \\
\hline LA1/Lcphth & $0.88-1.22(1.00)$ & $\begin{array}{l}\text { short, hardly reach } \\
\text { the middle of the } \\
\text { cephalothorax }\end{array}$ & $\begin{array}{l}\text { reach the posterior } \\
\text { margin } \\
\text { of the cephalothorax }\end{array}$ & $\begin{array}{l}\text { short, usually reach } \\
\text { the middle of the } \\
\text { cephalothorax }\end{array}$ \\
\hline Color & white & white & green & $\begin{array}{l}\text { white, yellow, light } \\
\text { green }\end{array}$ \\
\hline
\end{tabular}

* - our data of 14 specimens, for which molecular data were obtained, confirming their attribution to a single phylogenetic group;

** - data of G.F. Mazepova (1978); the brackets indicate the average value of parameters. 
species may be the same. The values of the parameters $\mathrm{Tmi} / \mathrm{Tme}, \mathrm{Td} / \mathrm{Te}, \mathrm{Tl} / \mathrm{Wf}$ are shown in the description of $D$. galbinus and $D$. versutus but are unknown for $D$. improcerus. In the key to Baikal cyclopoid species, the ratio of an antennule length to a cephalothorax length (LA1/Lcphth), the width of the A1 first segment, and the body shape are used to separate $D$. improcerus, $D$. galbinus, and D. versutus (Mazepova, 1978).

For each of the 18 parameters, we obtained the values of the Fisher criterion (Table 1, F). The differences were considered statistically meaningful in the case when the level of significance was less than 0.05 ( $\mathrm{Pr}<0.05)$. For all of the selected parameters, specimens collected from four locations in the Southern Baikal did not reliably differ.

Specimens could be identified only up to the rank of the genus Diacyclops. Specimens are morphologically similar to $D$. galbinus $D$. improcerus, and $D$. versutus but, at the same time, have some differences from each of these three species (Table 2). The studied specimens differ from $D$. improcerus in larger body size and more elongated antennules; from $D$. versutus - in smaller values of the Tmi/Tme parameter, in larger values of the Tl/Wf and IAS/EAS parameters, and more elongated antennules; from $D$ galbinus - in coloration and a lower value of Lenp3P4/Wenp3P4. The available description of these species allows comparing only six morphometric parameters (Mazepova, 1950; 1962). Unfortunately, it is impossible to compare the collected material with the type material of D. galbinus, $D$. improcerus, and D. versutus since they are missing in public collections. According to the morphological and molecular data (Fig. 5), we attribute the studied specimens to a single taxonomic group, named VIG2, which is new for endemic cyclopoids from Lake Baikal. The rank of this taxonomic group, as well as the groups VIG1 and VIG3, remains unclear. The use of the hybridological method in the future would clarify this issue. Probably, a new combination of features in the VIG2 specimens caused difficulties in the taxonomic identification of cyclopoids and an inconsistency between the molecular and morphological data that we described previously (Mayor et al., 2017). We provide a description of the VIG2 females. The description is based on the morphological data of 14 specimens, for which molecular data were obtained, confirming their attribution to a single phylogenetic group. These specimens were collected in each of the four sampling locations described above. The description is based on the work of Hołynska and Dimante-Deimantovica (2016).

Body length 747 - $902 \mu \mathrm{m}$ (without caudal rami length). Chephalothorax length/width $0.9-1.2$, cephalothorax width/genital somite width $2.0-3.3$, prosome length/urosome length $1.2-1.4$.

Genital double-somite longer than its greatest width, $1.1-1.6$ (Fig. 1A, 1B). The posterior margins of the 1-st and 2-nd abdominal segments are smooth. The posterior margin of anal somite with a continuous row of spinules (Fig. 1E, 1F). Anal sinus is ornamented with two diagonal rows of minute spinules (Fig. 1C). Caudal rami length/width $2.8-3.6$, smooth on the inner side.
Lateral seta is inserted at a distance of $0.17-0.29$ ramus length measured from the posterior end. Dorsal seta is almost as long as terminal external seta, $\mathrm{Td}$ / Te $0.97-1.13$. Terminal internal seta is shorter than terminal external seta, Ti/Te $0.51-0.74$. Terminal median internal seta (Tmi) is the longest, it is 1.58 1.72 times as long as terminal median external seta (Tme). Relative lengths of caudal setae $\mathrm{Td}$, Ti, Tmi, Tme, and Te are $0.7-0.9,0.3-0.5,4.5-6.2,2.2-$ 2.8 , and $0.7-0.8$ times as long as caudal rami. Caudal setae Ti, Tmi, Tme, Te are setose; dorsal seta has setae at distal part; lateral seta is naked (Fig. 1F). There is a row of short spinules above the point of lateral seta insertion (Fig. 1D).

Antennule 11-segmented, reaching posterior margin of chephalothorax shield for most individuals, $0.88-1.22$. Length ratios of antennular segments from proximal end are $1.0,0.3,0.5,0.3,0.2,0.3,0.6,0.5$, $0.3,0.4$, and 0.5 . Spinules present on proximo-ventral surface of segment 1 (Fig. 2A, 2B).

The antenna consists of coxobasis and threesegmented endopodite, bearing 3, 1, 9, and 7 setae, respectively. The coxobasis ornamented with two rows of spinules on the ventral surface, a row of setae on the caudal surface (Fig. 2C) armed with two subequal naked setae on the distal inner corner and exopodal seta with short setules reaching the 3-rd endopodal segment (Fig. 2B, 2D). The first endopodal segment with smooth inner seta at 0.42 length and group of setae at the distal part of the caudal margin (Fig. 2C). The second and third endopodal segments are ornamented with one and two diagonal rows of spinules on the caudal surface (Fig. 2E).

Segmentation formula of P1 - P4 exopod/ endopod: 2/2.3/2.3/3.3/3 (Fig. 3A). Ultimate exopodal segment spine formula is 3.3.3.3, and setae formula is 5.4.4.4. Table 3 shows the P1 - P4 spine and seta formula. The P1-P4 coxa ornamented with two rows of spines on the right and left side of the frontal surface (Fig. 3B, 3D, 3E). P2 - P3 coxa has notched external corner and ornamented with a row of spines on the lateral surface. P2 - P4 basis ornamented with a row of spines on the central part of the frontal margin (Fig. 3D, 3E). The P4 intercoxal sclerite has two rows of long spines in the middle and on the distal margin of the caudal surface $(3 \mathrm{C}, \mathrm{F})$, and is smooth from the frontal one. P4 coxa ornamented with five groups of spines on the caudal surface. P4 endpodal segment 1.3 - 1.6 times as long as wide; inner apical spine on 3-rd endopodal segment $1.5-2.0$ as long as outer apical spine, $1.0-$ 1.4 as long as segment (Fig. 3F).

P5 ( Fig. 4A, 4B) relatively small, two-segmented. First segment broad and short, armed with single slender outer seta, $41 \mu \mathrm{m}$. Second segment cylindrical, 2.5 times as long as wide, armed with apical outer seta and subapical inner spine. Apical seta $(32 \mu \mathrm{m}) 1.9$ times as long as P5 distal segment, and 1.7 times as long as subapical spine.

VIG2 belongs to a taxonomically complex and rich in species composition genus Diacyclops that includes more than 100 species (Stoch, 2001). Along with the complex of $D$. improcerus, $D$. versutus, and 


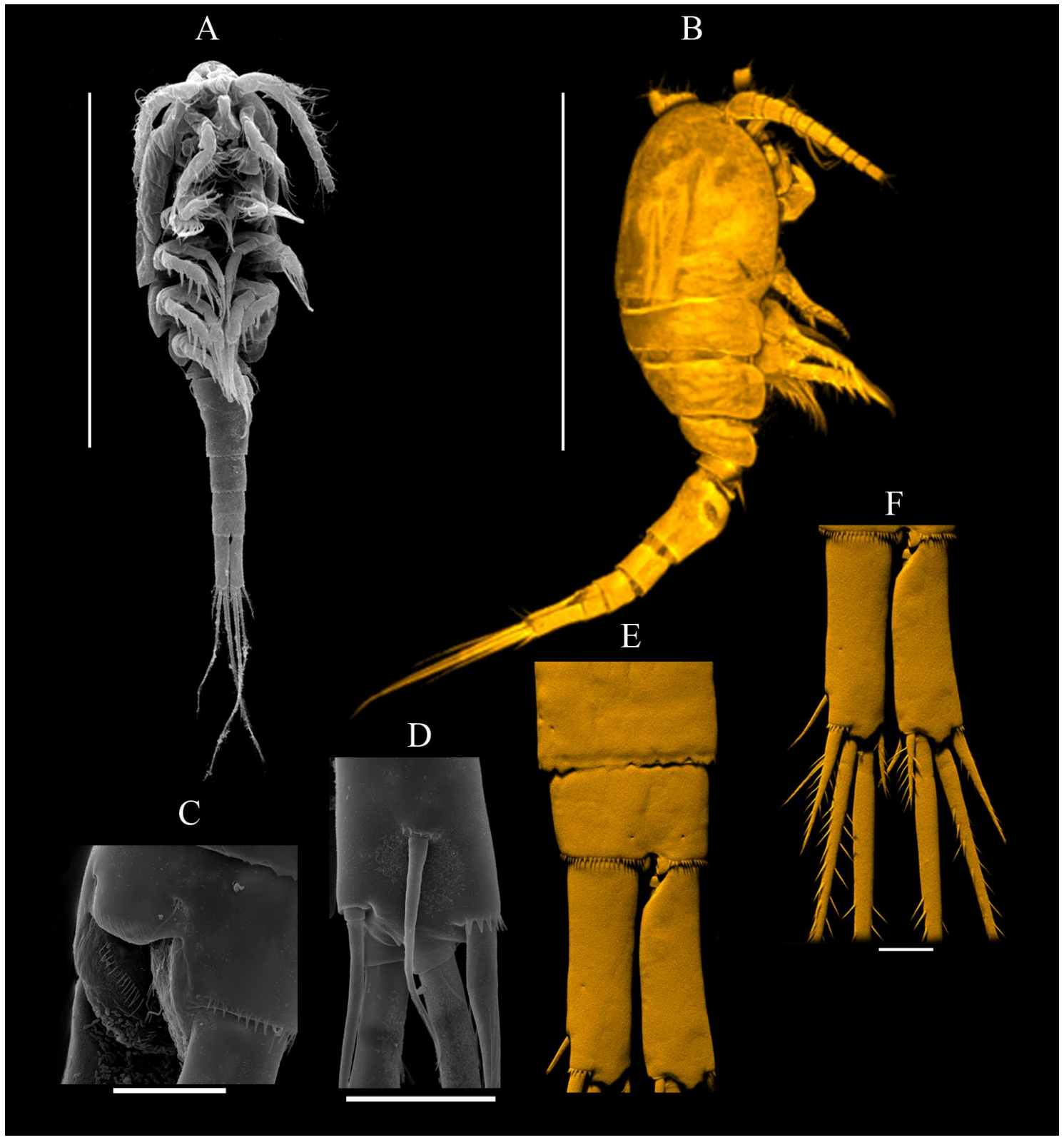

Fig. 1. Scanning electron (A, C, D) and confocal laser (B, E, F) micrographs of the taxonomic group VIG2, ㅇ. A - habitus, ventral. B - habitus, lateral. C - anal somite, lateral. D - lateral seta. E - the 2-nd abdominal segment, anal somite, caudal rami, dorsal. F - caudal rami, dorsal. Scale bars: $\mathbf{A}-\mathbf{B}=500 \mu \mathrm{m} ; \mathbf{C}-\mathbf{F}=20 \mu \mathrm{m}$.

D. galbinus, a new taxonomic group morphologically belongs to the group of species languidoides named after the first described species of this group Diacyclops languidoides languidoides (Lilljeborg, 1901). Among the Baikal cyclopoids, the new taxonomic group is the closest morphologically to D. galbinus. V.I. Monchenko (1974) suggested that $D$. galbinus is a synonym for $D$. languidoides moravicus Sterba, 1956. Representatives of VIG2 differ from $D$. languidoides moravicus by greater body length, Te/Ti and IAS / EAS parameters, and lower value of Lenp3P4/Wenp3P4 (Sterba, 1956). We believe that they belong to different species.

In our sampling sets of cyclopoids collected from the Southern Baikal, the adult VIG2 specimens are found in large numbers from late April to June, starting from the interstitial zone. Thus, this taxonomic group can be used as an indicator in the long-term dynamics and assessing the anthropogenic pressure on Lake Baikal. Probably, VIG2 may become a biological object in the study of chromatin diminution. The latter phenomenon has been found in D. galbinus (Ivankina et al., 2013). Molecular phylogenetic analysis

We obtained 15 nucleotide sequences of the mitochondrial COI gene fragment of $620-675 \mathrm{bp}$ in length. The data were obtained for three to seven specimens from each sampling set. The common fragment, excluding the missing data, was $482 \mathrm{bp}$. Analysis of this fragment showed the presence of six polymorphic positions, among which one was in the first position of the codon. Transversions were found in two positions. All substitutions were synonymous.

For the first time, we have obtained the nucleotide sequences of the rDNA fragment that includes ITS1 for the endemic Baikal cyclopoids. The rDNA nucleotide sequences with a length of 329-363 bp were determined for 10 specimens. The data were obtained for three to seven specimens from each sampling set. Upon aligning and removing regions with high divergence, the common fragment excluding the missing data was $252 \mathrm{bp}$. Analysis of this fragment showed the presence 


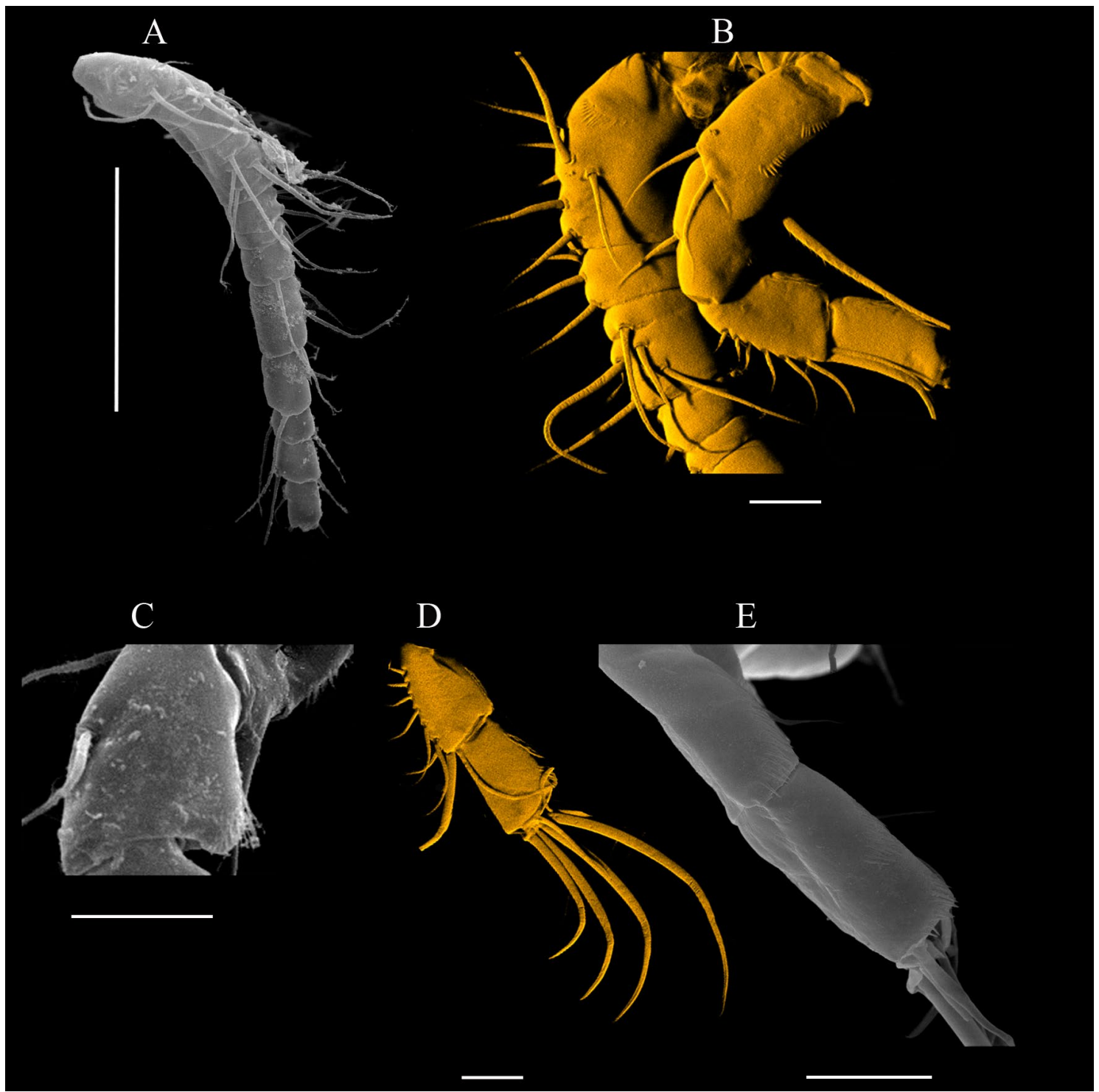

Fig. 2. Scanning electron (A, C, E) and confocal laser (B, D) micrographs of the taxonomic group VIG2, ${ }^{\circ}$. A - antennule, ventral. B - antennule: segments 1- 5, antenna, ventral. C - E - antenna. C - the 1-st endopodite, ventral. D - the 2-nd and 3-nd endopodits, ventral, lateral seta. $\mathbf{E}$ - the 2-nd and 3-nd endopodits, lateral. Scale bars: $\mathbf{A}=100 \mu \mathrm{m} ; \mathbf{B}-\mathbf{E}=20 \mu \mathrm{m}$.

of four polymorphic positions, in which only transitions were found.

Based on the obtained molecular data, phylogenetic schemes have been constructed (Fig. 5, 6). The tree topologies for the two molecular markers are consistent with each other. The nucleotide sequences of the VIG2 specimens form one monophyletic group. The values of genetic distances within this group are on average 0.005 and 0.003 according to COI and ITS1, respectively. At the same time, in the data set for the COI gene, the genetic distances between the nucleotide sequences belonging to the VIG2 and VIG1 phylogenetic groups are two orders of magnitude higher, averaging
0.21. In the data set for ITS1, the genetic distances between the nucleotide sequences of VIG2 and the endemic Baikal species D. arenosus (Mazepova, 1950) and D. jasnitskii (Mazepova, 1950) are on average 0.13 and 0.14 . The obtained values of intra- and interspecies genetic distances for both molecular markers are similar to those for Cyclopoida (Wyngaard et al., 2010; Miracle et al., 2013; Zagoskin et al., 2014; Krajicek et al., 2016).

The VIG2 specimens collected in Lake Baikal near the Listvyanka and Bolshiye Koty settlements as well as the town of Slyudyanka are genetically close to each other and form a panmictic population. At the same

Table 3. The armature of legs 1 - 4 of the VIG2 taxonomic group. Spines are denoted by Roman. setae by Arabic numerals

\begin{tabular}{|l|c|c|l|l|}
\hline & Coxopodite & Basipodite & Exopodite & Endopodite \\
\hline Leg 1 & $0-1$ & $1-1$ & I-1; III-2-3 & $0-1 ; 1-I-4$ \\
Leg 2 & $0-1$ & $1-0$ & I-1; I-1; II-I.1-3 & $0-1 ; 1-I .1-4$ \\
Leg 3 & $0-1$ & $1-0$ & I-1; I-1; II-I.1-3 & $0-1 ; 0-1 ; 1-I .1-3$ \\
Leg 4 & $0-1$ & $1-0$ & I-1; I-1; II-I.1-3 & $0-1 ; 0-2 ; 1-I I-2$ \\
\hline
\end{tabular}




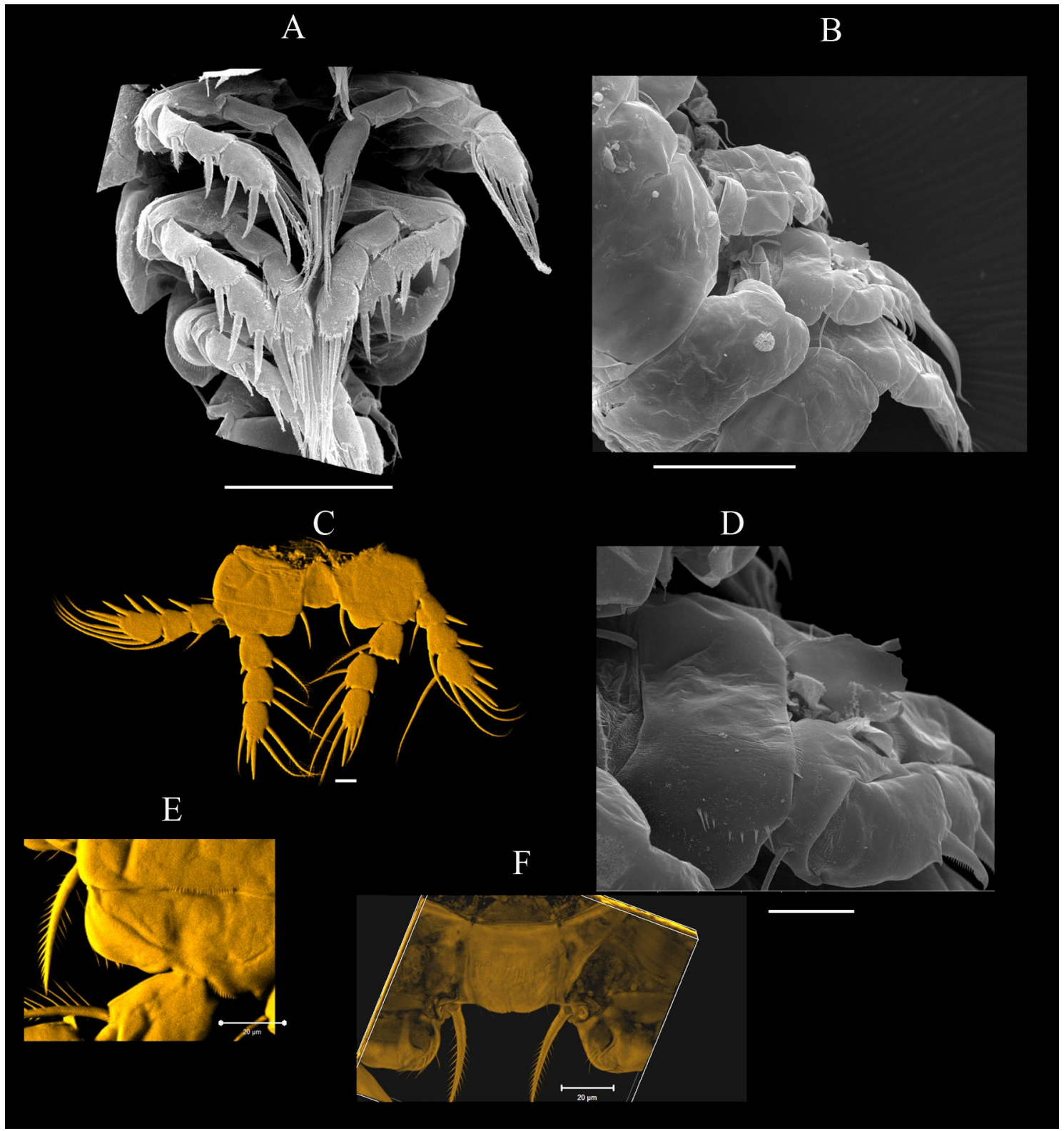

Fig. 3. Scanning electron (A, B, D) and confocal laser (C, E, F) micrographs of the taxonomic group VIG2, $\circ$. A - the 2-nd - 5-th pedigerous somites, ventral. B - Leg 1 - 3, lateral. C - leg 4, frontal. D - leg 2 coxopodite, lateral. E - leg 4, part of coxopodite, basipodite, frontal. F - leg 4, intercoxal sclerite, caudal. Scale bars: A - B = $100 \mu \mathrm{m} ; \mathbf{C}-\mathbf{F}=20 \mu \mathrm{m}$.

time, the specimens collected near the settlement of Bolshoye Goloustnoye show some genetic isolation for the COI gene from other representatives of this species (Fig. 5). At the same time, specimens do not differ in 18 morphometric parameters from Bolshoye Goloustnoye, Listvyanka, Bolshiye Koty and Slyudyanka.

\section{Conclusions}

1. Genetic and morphometric differences in the representatives of VIG2 from four locations of the Southern Baikal are low and comparable to the intraspecific level of differences.

2. Representatives of VIG2 belong to the new taxonomic group of Diacyclops in Lake Baikal and morphologically similar to D. galbinus, Diacyclops versutus, and $D$. improcerus but, at the same time, have a number of differences from each of these three species.

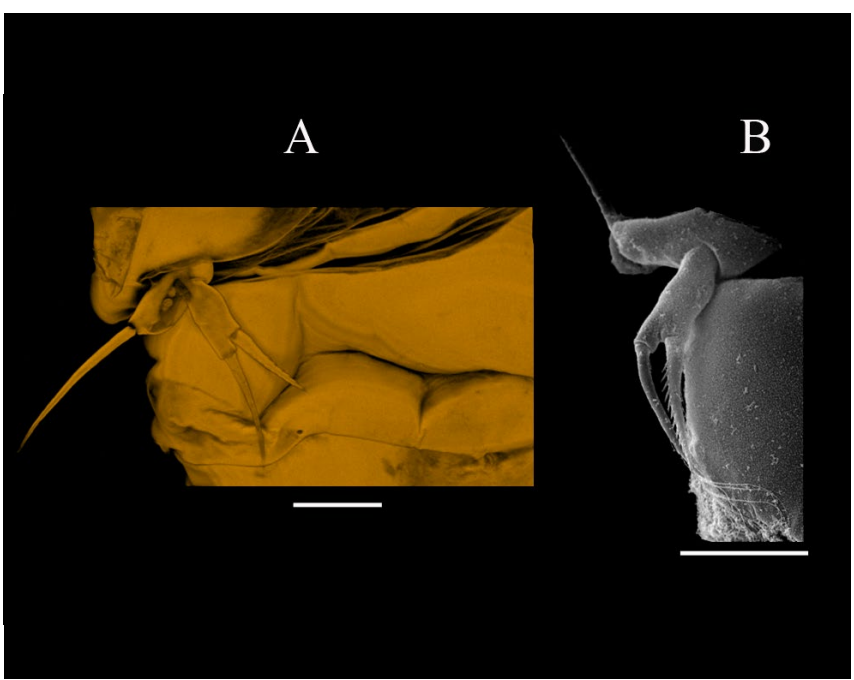

Fig. 4. Scanning electron (B) and confocal laser (A) micrographs of the taxonomic group VIG2, + . A, B - P5, frontal. Scale bars: $\mathbf{A}-\mathbf{B}=20 \mu \mathrm{m}$. 


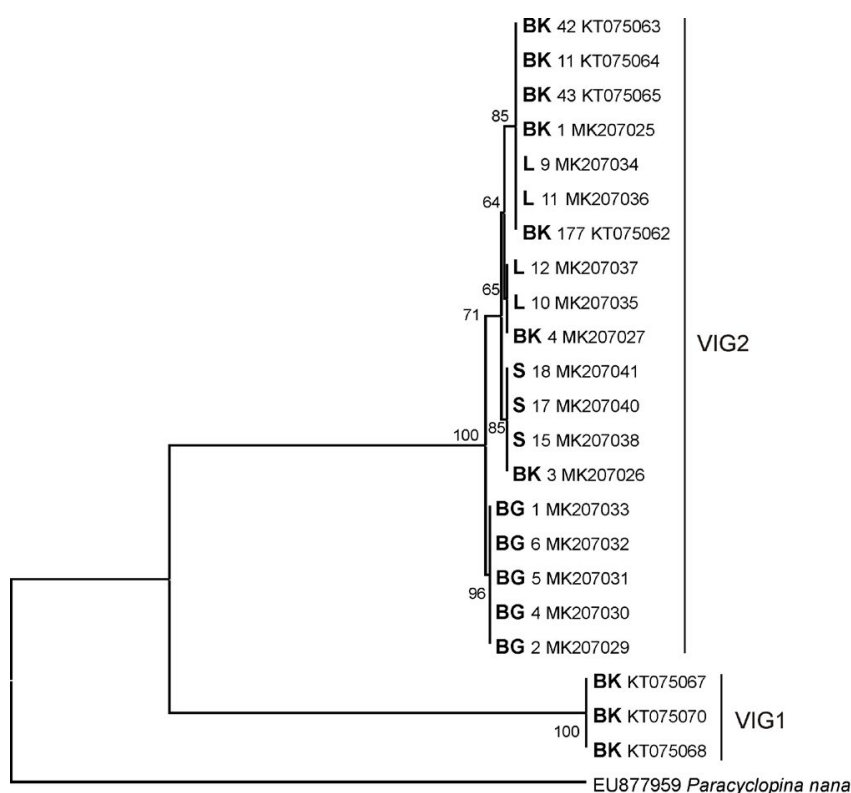

0.050

Fig. 5. Phylogenetic tree constructed based on the COI gene fragment by the maximum likelihood method (ML, T92 + I). The number in the node is the bootstrap value of the branching node support. The collecting site is indicated in the designation of nucleotide sequences: BK - Bolshiye Koty, L - Listvyanka, S - Slyudyanka, BG - Bolshoye Goloustnoe, specimen number and GenBank accession numbers.

\section{Acknowledgements}

We are grateful to M. Hołynska (Museum and Institute of Polish Academy of Sciences), E. Naumova, and Yu. Bukin (LIN SB RAS) for valuable comments on morphological analysis of the material and its statistical processing, and to Yu. Galimova (IMCB SB RAS) for the kindly provided nucleotide sequences. The SEM and CLSM studies were performed at the Instrumentation Center "Electronic Microscopy" of the Collective Instrumental Center "Ultramicroanalysis" (LIN SB RAS). The study was supported by the Russian Foundation for Basic research grant AAAA-A18-118032390006-1 «The study of phylogeny and morphology of Diacyclops versutus (Mazepova, 1962), D. improcerus (Mazepova, 1950), and D. galbinus (Mazepova, 1961) (Copepoda: Cyclopoida) from Lake Baikal» No. 18-34-00200 mol-a.

\section{References}

Blaha M., Hulak M., Sloukova J. et al. 2010. Molecular and morphological patterns across Acanthocyclops vernalis robustus species complex (Copepoda, Cyclopoida). Zoologica Scripta 39: 259-268.DOI:10.1111/j.1463-6409.2010.00422.x

Castresana J. 2000. Selection of conserved blocks from multiple alignments for their use in phylogenetic analysis. Molecular Biology and Evolution 17: 540-552.

Dussart B.H., Defaye D. 2006. World directory of Crustacea Copepoda of inland waters II, Cyclopiformes. Leiden: Backhuys Publisher.

Folmer O., Black M., Hoeh W. et al. 1994. DNA primers for amplification of mitochondrial cytochrome $\mathrm{c}$ oxidase subunit I from diverse metazoan invertebrates. Molecular Marine Biology and Biotechnology 3: 294-299.

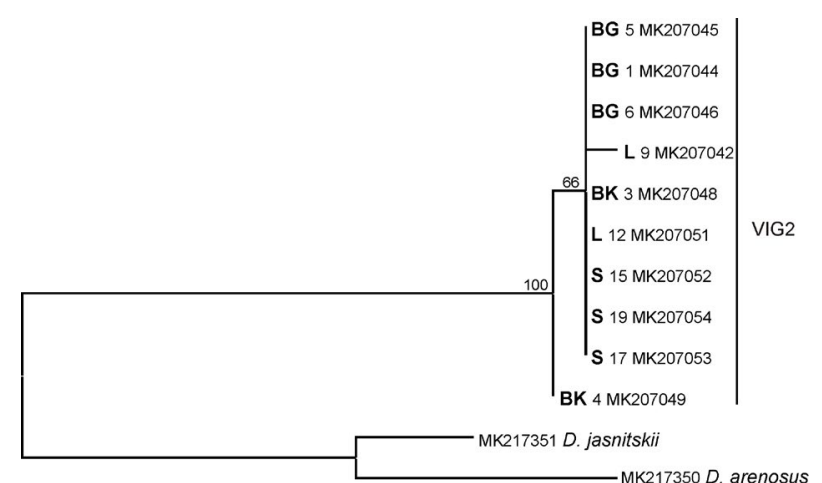

Fig. 6. Phylogenetic tree constructed based on ITS1 by the maximum likelihood method (ML, K2P + I). The number in the node is the bootstrap value of the branching node support. The collecting site is indicated in the designation of nucleotide sequences: BK - Bolshiye Koty, L - Listvyanka, S - Slyudyanka, BG - Bolshoye Goloustnoe, specimen number and GenBank accession numbers.

Hołynska M., Dimante-Deimantovica I. 2016. Redescription and taxonomic notes on Cyclops bohater Kozminski, 1933 and Cyclops lacustris G.O. Sars, 1863 (Arthropoda, Crustacea), with an identification key to the Cyclops species of Fenno-Scandinavia. European Journal of Taxonomy 212: 1-31. DOI: 10.5852/ejt.2016.212

Ivankina E.A., Alekseeva A.L., Semeshin V.F. et al. 2013. Cytophotometric determination of genome size in two species of Cyclops Lake Baikal (Crustacea: Copepoda: Cyclopoida). Cell and Tissue Biology 7: 192-199. DOI: 10.1134/ S1990519X13020053

Karanovic T., Krajicek M. 2012. First molecular data on the western Australian Diacyclops (Copepoda, Cyclopoida) confirm morpho-species but question size differentiation and monophyly of the Alticola-group. Crustaceana 85: 1549-1569. DOI: $10.1163 / 156854012 X 651709$

Kozminski Z. 1936. Morfometrische und ökologische Untersuchungen an Cyclopiden der strenuus-Gruppe. Internationale Revue der gesamten Hydrobiologie und Hydrographie [International Review of Hydrobiology] 33: 161-240. (in German)

Krajicek M., Fott J., Miracle M.R. et al. 2016. The genus Cyclops (Copepoda, Cyclopoida) in Europe. Zoologica Scripta: 671-682. DOI:10.1111/zsc.12183

Kumar S., Stecher G., Tamura K. 2016. Mega7: molecular evolutionary genetic analysis version 7.0 for bigger datasets. Molecular Biolology and Evolution 33: 1870-1874. DOI: 10.1093/molbev/msw054

Laforsch C., Tollrian R. 2000. A new preparation technique of daphnids for scanning electron microscopy using hexamethyldisilazane. Archiv für Hydrobiologie [Archive for Hydrobiology] 149: 587-596.

Lajus D., Alekseev V. 2000. Components of morphological variation in Baikalian endemial cyclopid Acanthocyclops signifier complex from different localities. Hydrobiologia 417: 25-35. 
Mazepova G.F. 1950. New species of Cyclopoids from Lake Baikal. Izvestiya Akademii Nauk SSSR. Seriya biologicheskaya [Bulletin of the USSR Academy of Sciences. Biological sciences] 75: 865-868. (in Russian)

Mazepova G.F. 1962. The benthic Cyclopoids of Southern Baikal. In: Bazikalova A.Y. (Ed.), Systematics and ecology of crustaceans of Baikal. Leningrad, pp. 172-195. (in Russian)

Mazepova G.F. 1978. Cyclopoids of Lake Baikal. Novosibirsk: Nauka. (in Russian)

Mayor T.Y., Sheveleva N.G., Sukhanova L.V. et al. 2010. Molecular-phylogenetic analysis of cyclopoids (Copepoda: Cyclopoida) from Lake Baikal and its water catchment. Russian Journal of Genetics 46: 1373-1380. DOI: 10.1134/ S102279541011013X

Mayor T.Y., Galimova Y.A., Sheveleva N.G. et al. 2017. Molecular-phylogenetic analysis of Diacyclops and Acanthocyclops (Copepoda: Cyclopoida) from Lake Baikal based on COI gene. Russian Journal of Genetics 53: 1-7. DOI: 10.1134/S1022795417020041

Mayor T.Y., Zaidykov I.Y., Galimova Y.A. et al. 2018. Molecular phylogeny of Diacyclops versutus (Mazepova, 1961), D. improcerus (Mazepova, 1950) and D. galbinus (Mazepova, 1961) (Copepoda: Cyclopoida) from Lake Baikal. In: International Conference "Freshwater ecosystems - Key problems", pp. 224-225.

Michels J., Büntzow M. 2010. Assessement of Congo red as a fluorescence marker for the exoskeleton of small Crustaceans and the cuticle of Polychaetes. Journal of Microscopy 238: 95-101. DOI: 10.1111/j.1365-2818.2009.03360

Miracle M.R., Alekseev V., Monchenko V. et al. 2013. Molecular-genetic-based contribution to the taxonomy of the Acanthocyclops robustus group. Journal of Natural History 47: 863-888. DOI: 10.1080/00222933.2012.744432

Monchenko V.I. 1974. Gnathostoma Cyclopoida, Cyclopidae. Fauna of Ukraine. Kiev: Naukova dumka. (in Ukrainian)

Monchenko V.I. 2000. Cryptic species in Diacyclops bicuspidatus (Copepoda: Cyclopoida): evidence from crossbreeding studies. Hydrobiologia 417: 101-107.

Phillips R.P., Matsuoka M.P., Konon I. et al. 2000. Phylogenetic analysis of mitochondrial and nuclear sequences supports inclusion of Acantholingua ohridana in the genus Salmo. Copea 2: 546-550.
R Core Team. 2017. R: a language and environment for statistical computing. Vienna: R Foundation for Statistical Computing. https://www.R-project.org/.

Rozas J., Sanchez-DelBarrio J.C., Messeguer X. 2003. DnaSP, DNA polymorphism analyses by the coalescent and other methods. Bioinformatics 19: 2496-2497.

Sheveleva N.G., Mirabdulaev I.M., Ivankina E.A. et al. 2012. The species composition and ecology of Cyclopoids in Lake Baikal. In: International Conference "Actual problems of studying of the Crustaceans of continental waters", pp. 319-322. (in Russian)

Sterba O. 1956. Vzacni a novi korysi z nasich krasvych vod. Biologia 11: 385-403. (in Slovak)

Stoch F. 2001. How many species of Diacyclops? New taxonomic characters and species richness in a freshwater cyclopid genus (Copepoda, Cyclopoida). Hydrobiologia 453/454: 525-531.

Sukhikh N., Alekseev V. 2015. Genetic and morphological heterogeneity within Eucyclops serrulatus (Fischer,1851) (Crustacea: Copepoda: Cyclopidae). Journal of Natural History 49: 2929-2953. DOI: 10.1080/00222933.2015.1056267

Timoshkin O.A. 2001. Lake Baikal: fauna diversity, problems of its immiscibility and origin, ecology and "exotic" communities. In: Timoshkin O.A. (Ed.), Index of animal species inhabiting Lake Baikal and its catchment area. Novosibirsk, pp. 16-74. (in Russian)

Ueda H., Yamaguchi A., Saitoh S. et al. 2011. Speciation of two salinity-associated size forms of Oithona dissimilis (Copepoda: Cyclopoida) in eustuaries. Journal of Natural History 45:2069-2079.DOI:10.1080/00222933.2011.574801

Wyngaard G.A., Hołyńska M., Schulte J.A. II. 2010. Phylogeny of the freshwater copepod Mesocyclops (Crustacea: Cyclopidae) based on combined molecular and morphological data, with notes on biogeography. Molecular Phylogenetics and Evolution 55: 753-764. DOI: 10.1016/j. ympev.2010.02.029

Zagoskin M.V., Lazareva V.I., Grishanin A.K. et al. 2014. Phylogenetic information content of Copepoda ribosomal DNA repeat units: ITS1 and ITS2 impact. BioMed Research International 2014. DOI: 10.1155/2014/926342

Zaidykov I.Yu., Naumova E.Yu. 2011. The fine morphology of mouth parts of Epischura chankensis Rylov, 1928 (Copepoda, Calanoida). Vladimir Ya. Levanidov's Biennial Memorial Meetings 5: 182-186. 